\title{
Cistercian Worlds. Conferência Internacional
}

Cistercian Worlds. International Conference

\section{Catarina Fernandes Barreira}

\section{(2) OpenEdition}

\section{Journals}

Edição electrónica

URL: https://journals.openedition.org/medievalista/5222

ISSN: 1646-740X

\section{Editora}

Instituto de Estudos Medievais - FCSH-UNL

\section{Refêrencia eletrónica}

Catarina Fernandes Barreira, «Cistercian Worlds. Conferência Internacional», Medievalista [Online], 31 2022, posto online no dia 01 janeiro 2022, consultado o 02 fevereiro 2022. URL: http:// journals.openedition.org/medievalista/5222

Este documento foi criado de forma automática no dia 2 fevereiro 2022.

\section{c) (i) (8)}

Mediavalista está licenciado com uma Licença Creative Commons - Atribuição-NãoComercial 4.0 Internacional. 


\title{
Cistercian Worlds. Conferência Internacional
}

\author{
Cistercian Worlds. International Conference
}

\author{
Catarina Fernandes Barreira
}

\section{NOTA DO EDITOR}

Data recepção do artigo / Received for publication: 24 de Novembro de 2021

1 O congresso internacional Cistercian Worlds foi uma iniciativa de Emmie Rose PriceGoodfellow e Jack Ford, dois jovens investigadores do Centre for Medieval Studies, da Universidade de York, que decorreu por zoom nos dias 1 e 2 de julho de 2021.

$\mathrm{O}$ congresso pretendia debater de que modo os diferentes contextos, a sua variedade e características afetaram as várias comunidades cistercienses, ao longo dos séculos, bem como os seus membros, e como foi construído o conceito de "ser cisterciense" na sociedade medieval. O que significava "ser cisterciense"? Como se construiu esta identidade na arte, na liturgia e na espiritualidade? Como é que esta identidade operou nos diversos contextos político-sociais? Como foi entendida por patronos e mecenas da época? Como se construíram as redes cistercienses? De que modo operaram? Todas estas questões serviram de ponto de partida para o debate, apoiado nas investigações sobre a Ordem de Cister feitas nas últimas décadas.

o congresso decorreu num formato de comunicações plenárias (por convite) e sessões paralelas (resultantes da resposta ao call for papers), e contou com a participação de cerca de meia centena de intervenientes, entre keynotes, oradores e moderadores, um formato que estimulou o debate e permitiu a troca de ideias entre investigadores mais jovens e outros com mais experiência.

4 A conferência de abertura foi proferida por Emilia Jamroziak (Universidade de Leeds), que dissertou sobre o tema Cistercian Studies in the Twenty-first Century and the Journey 
Ahead, trazendo para o debate os desafios que se colocam na atualidade aos investigadores especialistas em estudos cistercienses.

5 O Instituto de Estudos Medievais (IEM, FCSH NOVA) e os projetos de investigação Horizontes cistercienses. Estudar e caracterizar um scriptorium medieval e a sua produção: Alcobaça. Identidades locais e uniformidade litúrgica em diálogo (PTDC/ART-HIS/29522/2017) e Livros, rituais e espaço num Mosteiro Cisterciense feminino. Viver, ler e rezar em Lorvão nos séculos XIII a XVI (PTDC/ART-HIS/0739/2020) estiveram representados através de três painéis, com a designação-chapéu Cistercian Worlds in Portugal, onde comunicaram cerca de uma dezena dos seus investigadores.

6 A participação portuguesa teve início com uma breve apresentação, pela mão da investigadora principal, Catarina Fernandes Barreira (IEM, NOVA FCSH), do projeto Horizontes Cistercienses, já no seu terceiro ano de funcionamento, de forma a contextualizar os três painéis.

7 De seguida, teve início o primeiro painel dedicado ao tema Cistercian worlds in Portugal Worlds in Flux, o qual abriu com a conferência de Jonathan Wilson (IEM, FCSH NOVA), doutorado contratado do projeto Horizontes Cistercienses, sobre The Early Private Documents of Santa Maria de Alcobaça. Nesta conferência, o referido investigador apresentou um conjunto constituído por cerca de uma centena de diplomas coevos da fundação do Mosteiro de Alcobaça, até 1200, que documentam as relações desta comunidade com outras instituições, nacionais e internacionais, em que destacou o papel de Cîteaux e de Clairvaux. Seguiu-se a comunicação de Maria João Branco (IEM, NOVA FCSH), intitulada Canon Law in Alcobaça: a contradiction in terms?, em que foi abordado o papel desempenhado pelos monges de Alcobaça como juízes delegados e como conselheiros ou representantes do rei português entre a segunda metade do século XII e os inícios da centúria seguinte. Maria João Branco destacou o papel destes homens, as razões da sua escolha e os casos em que estiveram envolvidos, bem como a sua relação com o rei de Portugal, o papado e a Ordem de Cister. Este primeiro painel terminou com a comunicação de João Luís Fontes (IEM, NOVA FCSH) e Paulo Lopes (IEM, NOVA FCSH), intitulada A failed project: the fifteenth-century portuguese launch of the Benedictine Observance, através da qual os dois investigadores abordaram, no contexto português de inícios do século XV, o papel do abade D. Gomes Eanes e a tentativa de introdução da reforma beneditina em Portugal pelo rei D. João I e pelo seu sucessor, D. Duarte, a partir de uma análise da correspondência trocada pelo abade e dos documentos do Mosteiro de Alcobaça.

o segundo painel foi dedicado ao tema Manuscripts: materiality and content in late twelfth century Portugal e teve início com uma comunicação de Catarina Fernandes Barreira (IEM, NOVA FCSH): Three Books from Alcobaça - a View from the Liturgy. Nesta, a investigadora apresentou, de forma breve, três códices litúrgicos com origem no scriptorium de Alcobaça, estudados no âmbito do projeto Horizontes Cistercienses. Por intermédio desse estudo, foi possível avançar com a respetiva datação crítica, percecionar o longo período em que estiveram a uso por parte da comunidade e, através do estudo da liturgia, as circunstâncias e modalidades em que foram utilizados. De seguida, foi a vez de Conceição Casanova, co-investigadora principal dos projetos (REQUIMTE, NOVA FCT), e Catarina Gonçalves, bolseira de investigação do projeto, ambas da Faculdade de Ciência e Tecnologia da Universidade Nova de Lisboa, apresentarem o estudo Bookbinding through Time - Singularity and Regularity in Santa Maria de Alcobaça. Nesta comunicação foram apresentadas as potencialidades de um 
exame material rigoroso à evolução das técnicas de encadernação de um conjunto de códices originários do Mosteiro de Alcobaça, questionando que dados e informações se poderão retirar de tal análise e de que modo essas informações enriquecem o conhecimento que temos sobre a trajetória biográfica destes livros. Por fim, este painel ficou concluído com a apresentação das investigadoras do Laboratório HERCULES, da Universidade de Évora, Catarina Miguel, Silvia Bottura-Scardina e Shatila Algaf, dedicada ao tema Pigments, Paints and Blushes - the Palate of Illumination in early Alcobaça. Nesta comunicação foram apresentadas as composições materiais (isto é, a nível molecular, e usando técnicas laboratoriais não invasivas) dos três códices litúrgicos já mencionados, o que permitiu contextualizar os materiais usados no scriptorium alcobacense nos seus primeiros tempos e perceber como se fez a sua evolução ao longo dos séculos, através da análise material daquilo que foi sendo adicionado aos códices em épocas posteriores. Permitiu ainda compreender de que modo o scriptorium alcobacense também construiu a sua identidade através dos materiais usados, em relação a outros mosteiros como Clairvaux.

9 A terceira e última sessão foi dedicada aos mosteiros femininos em Portugal (Cistercian Women's Houses in the Iberian Far-West) e abriu com a apresentação de Luís Miguel Rêpas (IEM, NOVA FCSH): The Wives of Christ: female Cistercian communities in the Middle Ages. Esta intervenção centrou-se numa visão comparativa das sete comunidades cistercienses portuguesas, todas instituídas no século XIII, mas muito diferentes entre si. Estas disparidades tiveram origem, por um lado, no contexto da sua fundação e, por outro, na localização de cada uma destas casas monásticas, e na sua implantação numa rede conventual mais vasta, que acabou por se refletir na maior ou menor capacidade de recrutamento das mesmas e, sobretudo, no estatuto social das mulheres que compunham estas comunidades. Seguiu-se uma intervenção de Catarina Fernandes Barreira (IEM, NOVA FCSH), investigadora principal, de Conceição Casanova, coinvestigadora principal (REQUIMTE, NOVA FCT), e de Catarina Miguel (Laboratório HERCULES, Universidade de Évora), a propósito do projeto recém-aprovado sobre o Mosteiro de Lorvão: Four Centuries of Books, rituals and nuns; Lorvão from the thirteenth to sixteenth centuries. Nesta intervenção as investigadoras apresentaram os objetivos e as linhas gerais do projeto, bem como as tarefas a desenvolver pela equipa. Por fim, a participação portuguesa foi encerrada com a intervenção de Mário Farelo (IEM, NOVA FCSH), e Luís Miguel Rêpas (IEM, NOVA FCSH): Visitations and Revelations: recent discoveries from the late fifteenth century. Esta comunicação incidiu na apresentação do projeto editorial de publicação de um conjunto de visitações medievais a mosteiros portugueses, na sua grande maioria inéditas, sublinhando algumas das suas potencialidades para o estudo das comunidades cistercienses femininas na segunda metade do século XV, com informações significativas ao nível dos espaços monásticos.

Podemos dizer com satisfação que os resultados apresentados nestes três painéis e, em particular, o trabalho interdisciplinar desenvolvido até ao momento pelo projeto Cistercian Horizons tiveram um impacto significativo na comunidade internacional, quer pelo seu pioneirismo, quer pelas metodologias desenvolvidas pela equipa, quer ainda pela qualidade e quantidade de informações recolhidas até ao momento.

11 As outras sessões deste congresso foram dedicadas a diversas facetas dos Cistercienses, como o pensamento cisterciense, a sua diversidade e o modo como escreveram a sua história, ou o papel das mulheres na liturgia e na espiritualidade. Versaram ainda sobre as paisagens cistercienses, os contactos entre comunidades, o modo como os 
cistercienses viram "o outro", a arte cisterciense, os seus mecenas ou os modos de viver a enfermidade e a morte. Esta diversidade temática estendeu-se por uma vasta área geográfica, desde a Península Ibérica aos territórios da Dinamarca e da Noruega, passando pelas Ilhas Britânicas.

Destacamos algumas destas sessões, como a dedicada às comunidades cistercienses femininas: Cistercian Women: Liturgy, Spirituality and Power, em particular a primeira comunicação, de Elizabeth Freeman (Escola de Humanidades da Universidade da Tasmânia), intitulada Medieval Cistercian Nunneries and Their "Outdated" Liturgical and Consuetudines Manuscripts, que refletia sobre alguns manuscritos litúrgicos e de apoio à prática litúrgica, com origem em mosteiros masculinos, que acabaram por fazer parte de mosteiros femininos. A investigadora pretendia refletir sobre as questões em torno das diferenças entre códices de casas masculinas e femininas, nomeadamente a partir de dois aspetos: a desatualização litúrgica, e as diferenças entre a prática litúrgica emanada do Capítulo Geral e a prática litúrgica local. Elizabeth Freeman partiu do conhecido Breviário cisterciense de 1147 oferecido às monjas de Saint Just cerca de dois séculos depois; do Breviário de Clairmarais e da tradução francesa dos Ecclesiastica OFFזia mais a Regra de São Bento, numa intervenção muito interessante.

Na sessão 2b, Cistercian Thought: Cognition, Law and Philosophy, destacamos a intervenção de Eduardo Carrero Santamaría (Universidade Autónoma de Barcelona), sobre The Ecclesiastica Officia through the Senses: An Approach to the Cistercian Ideal of Staging the Liturgy. Nesta intervenção, o investigador começou por mencionar, de forma breve, como nos podemos aproximar da sonoridade dos espaços monásticos e dos problemas em torno de uma "acústica cisterciense" (como se fez em Sénanque, Thoronet e Silvacane). Existem dificuldades em falar de "dispositivos acústicos" usados nas igrejas porque não nos chegaram provas de que funcionaram e também se desconhece se eram para projetar o som ou para o abafar. Daqui o investigador passou para os problemas de compreensão do som das leituras dos textos e de como os monges e os conversos ouviriam os sons no interior das igrejas monásticas, não esquecendo a presença do mobiliário, nomeadamente o coro, e a influência que isso poderia ter na perceção dos sons.

14 No segundo dia, o conferencista foi o professor Constant J. Mews (Centre for Religious Studies, Universidade de Monash, Austrália), que dissertou sobre o tópico Redefining the Soul in Cistercian Perspective: Reason, Afrect and the Path of Music, uma problematização feita a partir dos textos de vários autores, uns cistercienses, outros não.

Neste dia destacamos a sessão 4, dedicada ao tema Cistercian Networks, e a intervenção de Ghislain Baury (Le Mans Université), intitulada Cistercian Nunneries Networks in Castile (12th-13th centuries). Nesta, o investigador apresentou um projeto de investigação, intitulado RECIMA - Réseaux cisterciens au Moyen Âge, que pretende cruzar os estudos em rede com os estudos cistercienses, e que se centra nos mosteiros situados em Castela nos séculos XII e XIII. A partir da documentação existente, num total de 2500 textos sobreviventes, das três dúzias e meia de mosteiros existentes, foi constituída uma base de dados, onde cerca de 700 documentos testemunham ocorrências e/ou contactos entre dois mosteiros femininos ou entre uma casa feminina e uma masculina (para o ilustrar, Ghislain Baury mostrou algumas representações gráficas destas redes institucionais). Das análises (sociogramas) a estas ocorrências podemos perceber a existência de laços fortes e fracos entre as comunidades femininas ou entre estas e os mosteiros masculinos. 

Kennedy (Universidade de Yale) debateu questões em torno da doença e da morte em contexto cisterciense (Crip Time in the Medieval Monastery: Cistercian Writers on the TimeScapes of Infirmity, c.1150-1250) e Edmund Wareham (Saint Edmund Hall, Universidade de Oxford), que se deteve nos rituais litúrgicos relacionados com a morte em comunidades femininas cistercienses alemãs, em tempos de reforma (From this World to the Next: Rituals around Death in South-West German Cistercian Nunneries). Na primeira intervenção, de Amelia Kennedy, foram analisadas narrativas monásticas relativas à enfermidade para perceber de que modo estas se entrosaram com histórias de milagres cistercienses e com as vitae dos séculos XII e XIII. Apesar de os escritores cistercienses terem olhado para as enfermidades e para o tempo passado nas enfermarias dos mosteiros como algo negativo, como uma interrupção do progresso de edificação espiritual, estas narrativas também reconheciam às doenças um valor redentor. Cistercian Art and Architecture II: Royal Connections, em que a intervenção de Herbert González Zymla (Universidade Complutense de Madrid), intitulada Ceremonies and Architecture in the Monastery of Saint Mary of Piedra, se centrou na relação entre a arquitetura e a especificidade da performance litúrgica no Mosteiro de Santa Maria da Pedra, ao longo da Idade Média, a partir de um conjunto diversificado de fontes.

18 A terminar o congresso, a mesa-redonda final contou com a participação de Janet Burton (Universidade de Wales Trinity Saint David), Jesse Harrington (Universidade de Cambridge), Emilia Jamroziak (Universidade de Leeds), Amelia Kennedy (Universidade de Yale) e Martha G. Newman (Universidade do Texas, Austin), e proporcionou um debate bastante profícuo sobre (quase) todos os temas abordados nos dois dias de congresso, tendo sido moderada pelos dois organizadores do mesmo, Emmie Rose Price-Goodfellow e Jack Ford.

Este congresso de dois dias, organizado por um grupo de investigadores jovens e dinâmicos, foi, também, bastante significativo pelo facto de ter permitido aos estudiosos das temáticas cistercienses perceber quais são os trabalhos e as investigações que estão neste momento em curso, quer individuais, quer no âmbito de projetos de investigação, e por favorecer os contactos e a troca de ideias entre os participantes. Em última instância, também contribuiu para a disseminação das investigações em curso nas universidades e nos diversos centros de investigação que se dedicam ao estudo da Idade Média e, em particular, a estudos cistercienses.

\section{AUTOR}

\section{CATARINA FERNANDES BARREIRA}

Universidade Nova de Lisboa, Faculdade de Ciências Sociais e Humanas, Instituto de Estudos Medievais, 1070-312 Lisboa, Portugal. cbarreira@fcsh.unl.pt. https://orcid.org/ 0000-0002-0174-1025 